\title{
Lipid peroxides and atherosclerosis
}

\author{
M D Stringer, P G Görög, Azadeh Freeman, V V Kakkar
}

\begin{abstract}
Plasma lipid peroxide concentrations were measured in 100 patients with occlusive arterial disease proved angiographically (50 patients with ischaemic heart disease, 50 with peripheral arterial disease) and compared with values in 75 control patients with no clinical evidence of atherosclerosis. Lipid peroxide concentrations were significantly higher in patients both with ischaemic heart disease (median $4.37 \mu \mathrm{mol} / 1$ (interquartile range 3.85-5.75 $\mu \mathrm{mol} / \mathrm{l}) ; \mathrm{p}<0.001$ ) and with peripheral arterial disease (median 4.37 $\mu \mathrm{mol} / 1$ (3.88-5.21 $\mu \mathrm{mol} / \mathrm{l}) ; \quad \mathbf{p}<\mathbf{0 . 0 0 1}$ ) than in controls (median 3.65 $\mu \mathrm{mol} / \mathrm{l}$ (interquartile range 3.29-3.89 $\mu \mathrm{mol} / \mathrm{l}$ )). Overall there was a significant but weak correlation between plasma lipid peroxide and plasma triglyceride concentrations $\left(r_{s}=0.25 ; p<0.001\right)$ but not between plasma lipid peroxide and plasma total cholesterol concentrations. Furthermore, hypertension, obesity, diabetes, smoking, positive family history, and intake of $\beta$ blockers and thiazide diuretics were not associated with significant differences in lipid peroxide values.

This study provides clinical support to experimental data indicating that peroxidised lipids may be important in atherogenesis and its complications and also suggests that peroxidised lipids may provide an index of the severity of atherosclerosis.
\end{abstract}

\section{Introduction}

Half of all deaths in the industrialised world are attributed to atherosclerosis and its complications. Many factors have been examined in an attempt to identify an index of severity of the disease. Haematological variables such as raised concentrations of factor VIIc, factor VIIIc, and fibrinogen are significantly associated with risk of cardiovascular death ${ }^{1}$ but not with the presence or extent of coronary atherosclerosis. ${ }^{2}$ By contrast, plasma lipoprotein values show a significant correlation both with the prevalence and incidence of clinical ischaemic heart disease and with the number of angiographically defined coronary artery stenoses but bear no relation to the size of the atherosclerotic lesions or the presence of thrombotic occlusion. ${ }^{3}$ Additional correlates of disease severity would be invaluable not only in improving our ability to assess individual risk but also in aiding our understanding of the pathogenesis of atherosclerosis.

Lipid peroxides, formed by the peroxidation of unsaturated fatty acids, were first detected in atherosclerotic human aortas more than 30 years $\mathrm{ago}^{4}$ and a subsequent study confirmed a strong positive correlation between the severity of aortic atherosclerosis and the concentration of these compounds in the aortic wall. ${ }^{5}$ Several groups have since suggested that lipid peroxides may be important in the development of atherosclerosis. $^{6.9}$ This might help to explain the frequent occurrence of disease in normolipidaemic people. Following Yagi's description and subsequent refinement of a simple fluorometric assay for plasma lipid peroxides using the thiobarbituric acid reaction, ${ }^{10}$ raised concentrations of lipoperoxides have been found in diabetes (particularly in patients with angiopathy)," hyperlipidaemia, ${ }^{8}$ essential hypertension, ${ }^{12}$ and acutely after myocardial infarction ${ }^{13}$ and stroke. ${ }^{7}$

The aim of this study was to investigate the possibility that plasma lipid peroxide concentrations are chronically raised in patients with proved occlusive arterial disease, which would support their potential role in the pathogenesis of atherosclerosis.

\section{Patients and methods}

The sample study comprised 100 patients aged under 75 with angiographically proved occlusive arterial disease; 50 were patients with ischaemic heart disease awaiting coronary artery bypass surgery and 50 were patients with peripheral arterial disease scheduled for reconstructive vascular surgery. Venous blood samples were collected in a standard manner into $7 \cdot 5 \%$ disodium edetic acid Vacutainers from consenting patients after a 10-14 hour overnight fast. Control samples from 75 patients awaiting chiefly minor surgery for non-traumatic, non-metabolic disorders were obtained and processed in an identical manner. Most of these operations were for inguinal hernias, varicose veins, haemorrhoids, and upper gastrointestinal endoscopy. Controls did not include patients with clinical or electrocardiographic evidence of ischaemic heart disease or those with absent peripheral pulses or symptoms of peripheral vascular disease. The following clinical features were recorded: age, sex, height and weight, smoking habits, history of diabetes mellitus or essential hypertension, family history of ischaemic heart disease or peripheral arterial disease (one or more affected first degree relatives aged under 65), and medication. Patients with abnormal liver function values or renal failure were also excluded, together with patients who had had a recent myocardial infarction (within the past three months) or who had acute infections. No patient was receiving heparin. After centrifugation plasma samples were stored below $-20^{\circ} \mathrm{C}$ for up to three months.

\section{LIPID MEASUREMENTS}

\section{Lipid peroxides}

Plasma lipoperoxide concentrations were estimated by a modification of Yagi's fluorometric method. ${ }^{10}$ Plasma $(20 \mu \mathrm{l})$ was mixed with $1 \mathrm{ml} 12 \mathrm{~N}$ sulphuric acid in an Eppendorf tube and $0.5 \mathrm{ml} \mathrm{10 \%} \mathrm{phosphotungstic}$ acid added. After standing at room temperature for five minutes the mixture was centrifuged at $4000 \mathrm{rpm}$ for five minutes. The supernatant was discarded and the sediment thoroughly mixed with $1 \mathrm{ml} 12 \mathrm{~N}$ sulphuric acid before the centrifugation was repeated. The sediment was then resuspended in fresh thiobarbituric acid reagent $(1 \mathrm{ml}$ of a solution of $0.67 \%$
Correspondence to: $\mathrm{Mr}$ Stringer.

BrMed f 1989;298:281-4 
aqueous thiobarbituric acid in $0.5 \mathrm{M}$ trometamol (TRIS) buffer adjusted to $\mathrm{pH} 3 \cdot 2-3 \cdot 8$ with glacial acetic acid); mixed thoroughly, and heated at $95^{\circ} \mathrm{C}$ for one hour in an oil bath. After cooling at room temperature for one hour the suspension was centrifuged at $4000 \mathrm{rpm}$ for 10 minutes and the supernatant removed for fluorometric measurement $(515 \mathrm{~nm}$ excitation, $553 \mathrm{~nm}$ emission) in a Perkin-Elmer luminescence spectrometer.

A standard was obtained by reacting $0.5 \mathrm{nmol}$ malonaldehyde bis (diethylacetal) $98 \%$ (Sigma) with thiobarbituric acid reagent. Taking the fluorescence intensity of the standard solution as $F$ and that of the sample plasma as $f$ the lipoperoxide concentration $(L p)$ expressed in terms of malondialedehyde was: $\mathrm{Lp}=0.5 \times \mathrm{f} / \mathrm{F} \times 1.0 / 0.02=\mathrm{f} / \mathrm{F} \times 25(\mu \mathrm{mol} / \mathrm{l}$ plasma $)$. The intensity of fluorescence was linearly related to the malondialdehyde concentration up to $10 \mu \mathrm{mol} / \mathrm{l}$. All plasma samples were assessed in duplicate and repeated if there was $>5 \%$ difference between the parallels. The mean within assay variation for 20 replicate analyses of the same sample was $1 \cdot 8 \%$ and the mean between assay variation of 12 samples measured on five separate occasions $3 \cdot 0 \%$.

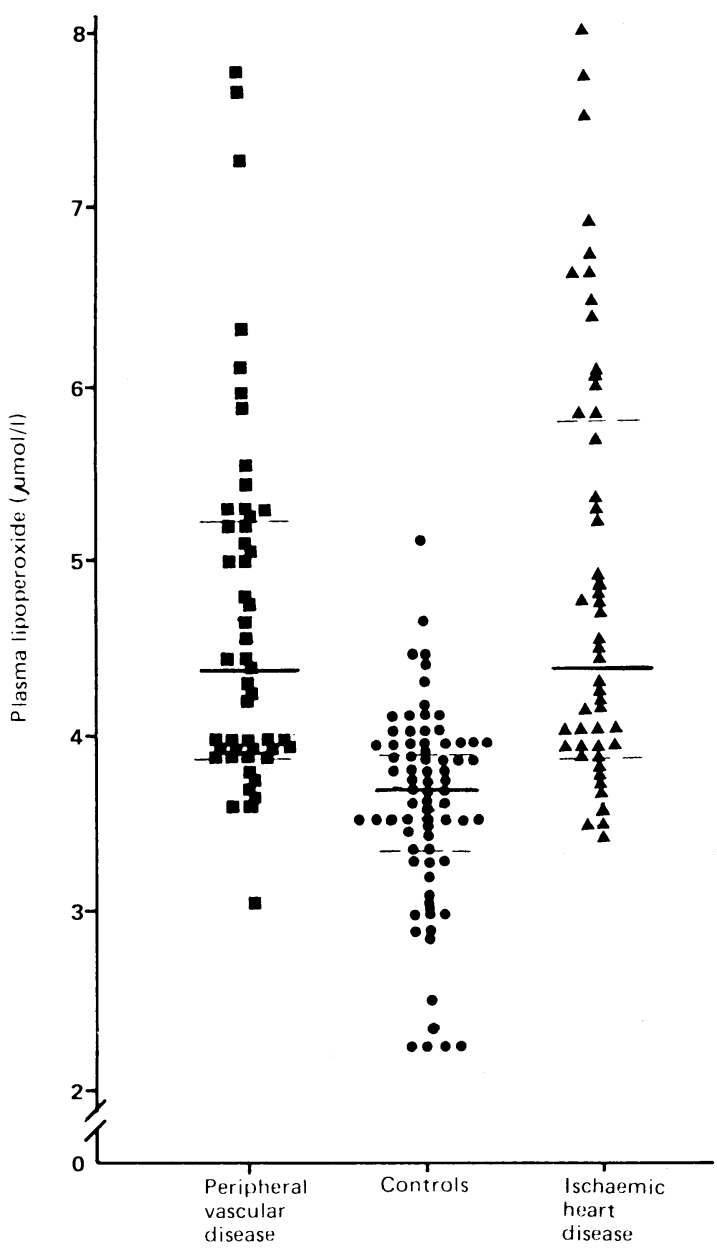

FIG 1-Plasma lipid peroxide concentrations in patients with atherosclerosis and controls expressed in terms of malondialdehyde concentrations ( $\mu$ mol/l). Bars are medians and interquartile ranges

Plasma concentrations of total cholesterol, triglycerides, and lipid peroxides in patients with occlusive arterial disease and controls. Values are medians (interquartile ranges in parentheses)

\begin{tabular}{lccc}
\hline & $\begin{array}{c}\text { Patients with ischaemic } \\
\text { heart disease } \\
(\mathbf{n}=50)\end{array}$ & $\begin{array}{c}\text { Controls } \\
(\mathbf{n}=75)\end{array}$ & $\begin{array}{c}\text { Patients with peripheral } \\
\text { arterial disease } \\
(\mathbf{n}=50)\end{array}$ \\
\hline Cholesterol $(\mathrm{mmol} / \mathrm{l})$ & $6 \cdot 35(5 \cdot 67-7 \cdot 50)^{\star}$ & $5 \cdot 60(4 \cdot 60-6 \cdot 20)$ & $6 \cdot 00(5 \cdot 13-6 \cdot 72)$ \\
Triglycerides $(\mathrm{mmol} / \mathrm{l})$ & $2 \cdot 00(1 \cdot 60-3 \cdot 00)^{\star}$ & $1 \cdot 20(0 \cdot 90-1 \cdot 70)$ & $1 \cdot 65(1 \cdot 27-2 \cdot 43)^{\star}$ \\
Lipoperoxides $(\mu \mathrm{mol} / \mathrm{l})$ & $4 \cdot 37(3 \cdot 85-5 \cdot 75)^{\star}$ & $3 \cdot 65(3 \cdot 29-3 \cdot 89)$ & $4 \cdot 37(3 \cdot 88-5 \cdot 21)^{\star}$ \\
\hline${ }^{\star}$ Con & &
\end{tabular}

\section{Total triglyceride and cholesterol concentrations}

Plasma total triglyceride and cholesterol concentrations were determined by standard automated procedures using a Cobas Bio (Roche) centrifugal analyser. The method for cholesterol used an enzymatic colorimetric procedure with cholesterol oxidase, and triglycerides were determined fluorometrically after enzymatic hydrolysis.

\section{STATISTICS}

Because of the non-normality of the data nonparametric methods of analysis were used. The Kruskal-Wallis statistic was used for comparison among multiple groups and the Wilcoxon unpaired statistic for comparison of two groups. Spearman rank correlation coefficients were calculated to assess the relation among plasma triglyceride, cholesterol, and lipid peroxide concentrations. Computer analysis was by the biomedical data package (program version, April 1985).

\section{Results}

Plasma lipid peroxide concentrations of patients with ischaemic heart disease (median 4.37 $\mu \mathrm{mol} / 1$ (interquartile range $3 \cdot 85-5 \cdot 75 \mu \mathrm{mol} / \mathrm{l})$ ) and peripheral arterial disease (median $4 \cdot 37 \mu \mathrm{mol} / 1(3 \cdot 88-5 \cdot 21 \mu \mathrm{mol} / \mathrm{l})$ ) were significantly greater than control values (median 3.65 $\mu \mathrm{mol} / \mathrm{l}$ (interquartile range 3.29-3.89 $\mu \mathrm{mol} / \mathrm{l}$ )) $\mathrm{p}<0.001$ ) (fig 1). The sex of the patients had no significant influence on values. The median age of patients with peripheral arterial disease (65 years, range 41-76; $\mathrm{p}<0.05$ ) was significantly higher than of patients with ischaemic heart disease (median 58 years, range 38-67) and controls (median 59 years, range 39-74), but as there was no significant correlation between plasma lipid peroxide concentrations and age in either the controls $\left(n=75 ; r_{s}=0.09\right.$; NS) or patients with atherosclerosis $\left(n=100 ; r_{s}=0.03 ; N S\right)$, this was considered unimportant. Plasma triglyceride concentrations were also significantly raised in patients with atherosclerosis as compared with controls, but plasma total cholesterol values were raised significantly only in patients with ischaemic heart disease (table).

Overall there was a significant positive correlation between triglyceride and total cholesterol values $\left(r_{s}=0.49 ; p<0.001\right)$, a weak significant correlation between plasma lipid peroxide and triglyceride values $\left(r_{s}=0.25 ; p<0.001\right)$, but no significant correlation between lipid peroxide and total cholesterol values $\left(r_{\mathrm{s}}=0 \cdot 13 ; \mathrm{NS}\right)$ (figs 2 and 3$)$.

Analysing controls and patients with atherosclerosis in two separate groups (Kruskal-Wallis statistic) failed to disclose any significant effect on plasma lipoperoxide concentrations due to hypertension, obesity (body mass index $\left(\mathrm{kg} / \mathrm{m}^{2}\right) \geqslant 25$ ), diabetes, smoking, and positive family history. Intake of $\beta$ blockers and thiazide diuretics was also not associated with any significant differences in lipid peroxide values. Furthermore, among patients with peripheral arterial disease there was no significant difference between those with critical ischaemia $(n=17)$ and those with claudication $(n=33)$.

Finally, we examined the effect on plasma lipid peroxide values of short term freezing (up to three months at below $-20^{\circ} \mathrm{C} ; \mathrm{n}=40$ ), delay between collecting the sample and separating the plasma (up to three hours; $n=24$ ), and fasting (samples taken after 10-14 hour fast compared with two to three hours after a meal; $n=20$ ). No significant differences were detected.

\section{Discussion}

This detailed controlled study shows that plasma lipid peroxide concentrations are raised in patients 


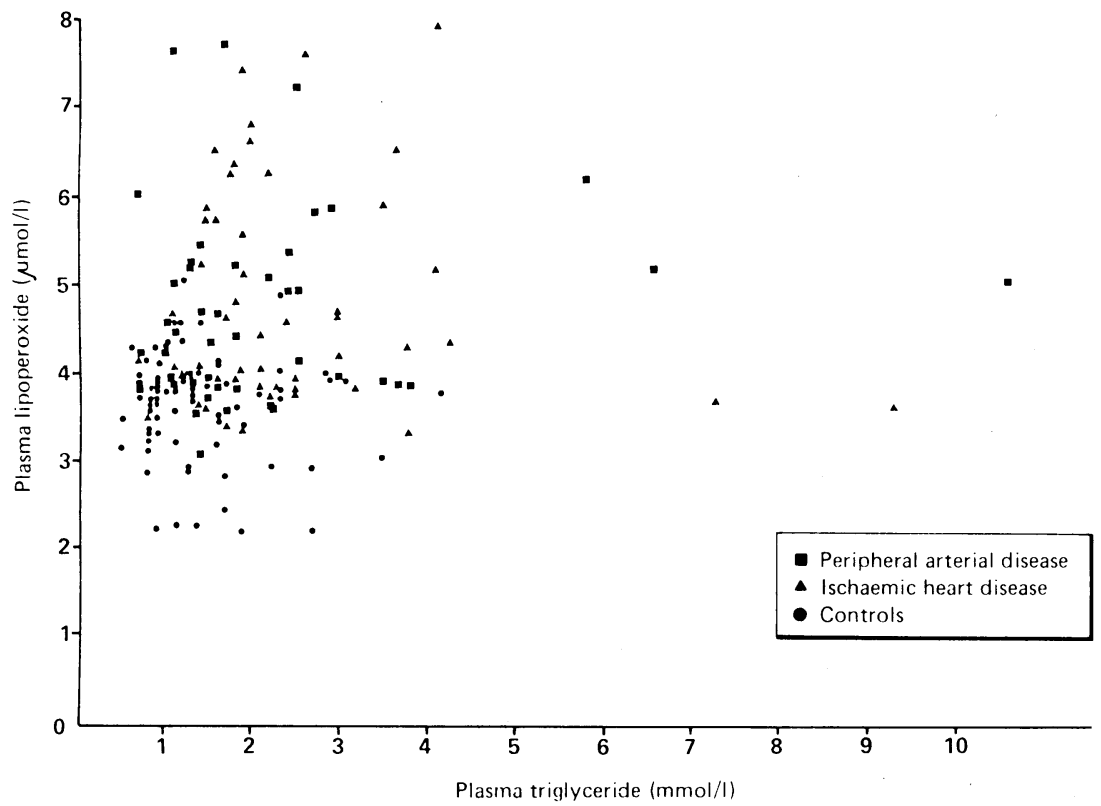

FIG 2-Plasma lipid peroxide concentrations in relation to plasma triglyceride values $\left(r_{s}=0.25 ; p<0 \cdot 001\right)$

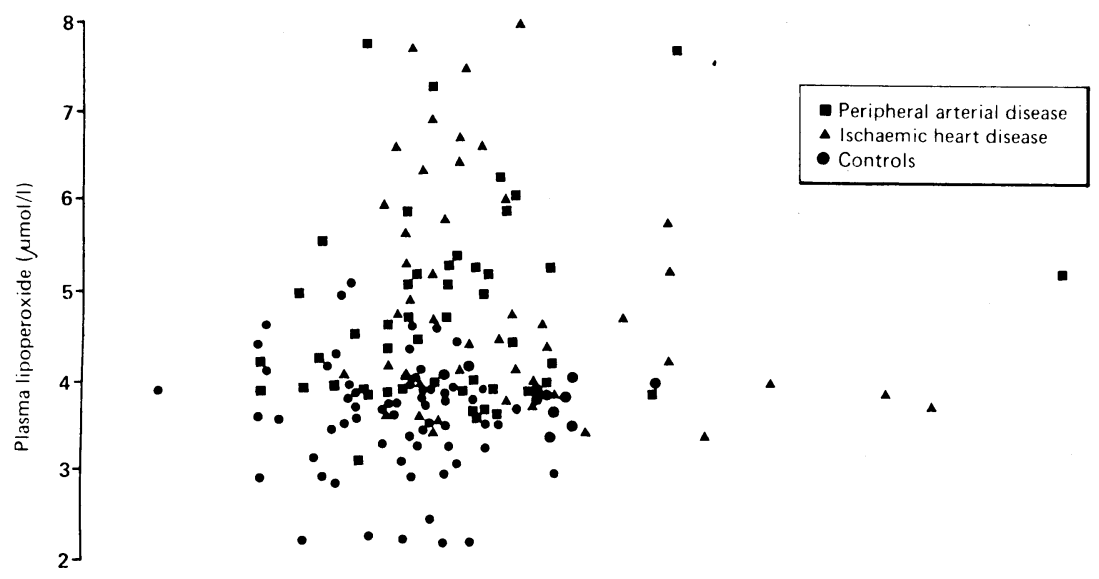

$\begin{array}{lllllllllllllll}1 & 2 & 3 & 4 & 5 & 6 & 7 & 8 & 9 & 10 & 11 & 12 & 13 & 14 & 15\end{array}$

Plasma cholesterol $(\mathrm{mmol} / \mathrm{l})$

FIG 3-Plasma lipid peroxide concentrations in relation to plasma cholesterol concentrations $\left(r_{s}=0 \cdot 13 ; N S\right)$

with atherosclerotic occlusive arterial disease. The lack of any significant difference in values in the subgroup of patients with critically ischaemic limbs - that is, as manifested by rest pain, ischaemic ulceration, or gangrene-suggests that raised lipid peroxide concentrations are not simply a reflection of tissue ischaemia. Interestingly, the median lipid peroxide concentrations in patients with ischaemic heart disease and peripheral arterial disease were identical, whereas raised lipoprotein concentrations are generally more frequent in patients with ischaemic heart disease than those with peripheral vascular disease. ${ }^{14}$

Lipid peroxides are derived from the oxidation of polyunsaturated fatty acids and their esters and are capable of further lipoperoxide production by a free radical chain reaction. For several reasons it is likely that peroxidation of lipids is an endogenous process: lipid peroxides have a comparatively short circulatory half life in laboratory animals ${ }^{15}$; their concentrations appear not to be influenced in the short term by dietary intake; acute changes occur after myocardial infarction $^{13}$; and antioxidants such as vitamin $\mathrm{E}$ inhibit lipid peroxidation in vivo. ${ }^{16}$ Furthermore, in vitro studies show that endothelial cells, monocytes, and neutrophils are all capable of free radical oxidation of low density lipoproteins. ${ }^{17} 18$

Estimation of plasma lipid peroxide concentrations by the thiobarbituric acid reaction is a well established, sensitive method which measures the amount of malondialdehyde formed as a breakdown product of lipoperoxides. ${ }^{19}$ The assay has been criticised for lack of specificity, but many of these problems have been eliminated or found to have negligible effects when Yagi's method is used. ${ }^{10}$ Moreover, there is a good correlation between the results obtained by Yagi's method and those achieved with high performance liquid chromatography..$^{20}$

There was no apparent relation between plasma lipid peroxides and plasma total cholesterol concentrations but the weak significant correlation with triglyceride values is not surprising. Nishigaki et al have analysed the lipid peroxide content of serum lipoprotein fractions in normal and diabetic subjects and found that very low density lipoproteins, low density lipoproteins, and high density lipoproteins were all vehicles for peroxidised lipids but that the low density fraction was associated with the biggest share.$^{21}$ Of human plasma lipoproteins, low density lipoproteins are the most susceptible to peroxidation,,$^{22}$ and this process results in many alterations in their composition and biological properties. The oxidised low density lipoprotein is recognised by scavenger receptors (independent of the normal apoprotein receptor), leading to an increased uptake by endothelial cells and macrophages ${ }^{2324}$ and accumulation of cholesterol esters in the monocyte or macrophage. Low density lipoprotein uptake by the scavenger receptor pathway is not regulated and thus the cell continues to acquire lipid. ${ }^{25}$ Moreover, this modified low density lipoprotein is cytotoxic to endothelial cells in vitro. ${ }^{26}{ }^{27}$ Lipid peroxides themselves are also capable of inhibiting antithrombin III activity, ${ }^{28}$ producing procoagulant activity, ${ }^{29}$ and enhancing platelet aggregation, ${ }^{7}$ all of which may be concerned in the complications of atherosclerosis. High density lipoproteins do not share these properties and experiments suggest that they may even protect low density lipoproteins from peroxidation. ${ }^{30}$

This constellation of effects - namely, endothelial cell injury, uncontrolled lipid uptake by macrophages, reduced endothelial prostacyclin synthesis, and associated thrombogenicity - have all been strongly implicated in the pathogenesis of atherosclerosis. ${ }^{16} 31$ The potential role of lipid peroxides in atherogenesis is further supported by the increase in serum and aortic lipid peroxide concentrations found in animals maintained with atherogenic diets ${ }^{72}$ and epidemiological data showing increased serum lipoperoxide concentrations in the children of parents suffering premature myocardial infarction. ${ }^{33}$ Further work is in progress to see whether plasma lipid peroxide values might provide a useful index of the severity of atherosclerosis.

We acknowledge the following for their contributions: the consultant surgeons at King's College Hospital for allowing us to study their patients; Dr C Moniz, Dr W J Marshall, and $\mathrm{Mr}$ J Keating, of the department of chemical pathology; Dr D Cooper, department of computing; R P A'Hern, of the department of computing, Royal Marsden Hospital, London; and Mrs B M Radcliffe for typing the manuscript. This study was supported by a Medical Research Council programme grant (No 973/756).

1 Meade TW, North WRS, Chakrabarti R, et al. Haemostatic function and cardiovascular death; early results of a prospective study. Lancet 1980;i: 1050-3.

2 Schmitz-Huebner U, Thompson SG, Balleisen L, et al. Lack of association between haemostatic variables and the presence or the extent of coronary atherosclerosis. Br Heart f 1988;59:287-91

3 Miller NE, Hammett F, Saltissi S, et al. Relation of angiographically defined coronary artery disease to plasma lipoprotein subfractions and apolipoproteins. Br Med f 1981;282:1741-4.

4 Glavind J, Hartmann S, Clemmensen J, Jessen KE, Dam H. Studies on the role of lipoperoxides in human pathology. II. The presence of peroxidized lipids in the atherosclerotic aorta. Acta Pathologica et Microbiologica Scandinavica 1952:30:1-6. 
5 Harland WA, Gilbert JD, Steel G, Brooks CJW. Lipids of human atheroma. Part 5. The occurrence of a new group of polar sterol esters in various stages of human atherosclerosis. Atherosclerosis 1971;13:239-46.

6 Dormandy JA, Hoare E, Khattab AH, Arrowsmith DE, Dormandy TL. Prognostic significance of rheological and biochemical findings in patients with intermitrent claudication. BrMed 7 1973:iv:581-3.

7 Goto Y. Lipid peroxides as a cause of vascular disease. In: Yagi K, ed. Lipid peroxides in biologv and medicine. New York: Academic Press Inc, 1982: 295-303.

8 Loeper J, Emerit J, Goy J, Bedu O, Loeper J. Lipid peroxidation during human atherosclerosis. IRCS fournal of Medical Science 1983;11:1034-5,

9 Yagi K. Increased serum lipid peroxides initiate atherogenesis. Bioassays 1984;1:58-60

10 Yagi K. Assay for serum lipid peroxide level and its clinical significance. In: Yagi $\mathrm{K}$, ed. Lipid peroxides in biology and medicine. New York: Academic Press, 1982:223-42.

11 Sato Y, Hotta N, Sakamoto N, Matsuoka S, Ohishi N, Yagi K. Lipid peroxide level in plasma of diabetic patients. Biochem Med 1979;21:104-7.

12 Uysal $\mathrm{M}$, Buler $\mathrm{H}$, Sener $\mathrm{D}, \mathrm{Oz} \mathrm{H}$. Lipid peroxidation in patients with essential hypertension. Int 7 Clin Pharmacol Res 1986;24:474-6.

13 Loeper J, Goy J, Bedu O, Rozensztajn L. Lipid peroxidation and protective enzymes during the course of myocardial infarction. Agents Actions 1987;22: $340-2$.

14 Greenhalgh RM, Lewis B, Rosengarten DS, Calnan JS, Mervart I, Martin P. Serum lipids and lipoproteins in peripheral vascular disease. Lancet 1971;ii:947-50.

15 Yagi K, Ohkawa H, Ohishi N, Yamashita M, Nakashima T. Lesion of aortic intima caused by intravenous administration of linoleic acid hydroperoxide. 7 Appl Biochem 1981;3:58-65.

16 Szczeklik A, Gryglewski RJ, Domagala B, Dworski R, Basista M. Dietary supplementation with vitamin $\mathrm{E}$ in hyperlipoproteinaemias: effects on supplementation with vitamin $\mathrm{E}$ in hyperlipoproteinaemias: effects on
plasma lipid peroxides, antioxidant activity, prostacyclin generation and plasma lipid peroxides, antioxidant activity, prostacycin

17 Steinbrecher UP, Parthasarathy S, Leake DS, Witztum JL, Steinberg D. Modification of low density lipoprotein by endothelial cells involves lipid peroxidation and degradation of low density lipoprotein phospholipids. Proc Natl Acad Sci USA 1984;81:3883-7.

18 Cathcart MK, Morel DW, Chisholm GM. Monocytes and neutrophils oxidize low density lipoprotein making it crtotoxic. I Leukocyle Biol 1985;38 $3+1-50$
19 Halliwell B, Gutteridge JM. Free radicals in biology and medicine. Oxford: Clarendon Press, 1985.

20 Therasse J, Lemonnier F. Determination of plasma lipoperoxidases by high performance liquid chromatography. $\mathcal{A}$ Chromalogr 1987:413:237-41.

21 Nishigaki I, Hagihara M, Tsunekawa H, Maseki M, Yagi K. Lipid peroxide levels of serum lipoprotein fractions of diabetic patients. Biochem Med $1981 ; 2: 373-8$

22 Szczeklik A, Gryglewski RJ, Domagala B, et al. Serum lipoproteins, lipid peroxides and prostacyclin biosynthesis in patients with coronary heart peroxides and prostacyclin biosynthesis

23 Hinsbergh VWM. Biologic generation and metabolic effects of oxidized lipoproteins. Agents Actions 1987;22:349-50.

24 Fogelman AM, Schechter I, Seager J, Hokom M, Child JS, Edwards PA. Malondialdehyde alteration of low density lipoproteins leads to cholesterol ester accumulation in human monocyte-macrophages. Proc Natl Acad Sci USA. 1980;77:2214-8.

25 Mitchinson MJ, Ball RY. Macrophages and atherogenesis. Lancet 1987;ii: $146-8$

26 Evensen SA, Galdal KJ, Nilsen E. LDL-induced cytotoxicity and its inhibition by anti-oxidant treatment in cultured human endothelial cells and fibroblasts. Atherosclerosis 1983;49:23-30.

27 Szczeklik A, Gryglewski RJ. Low density lipoproteins (LDL) are carriers for lipid peroxides and inhibit prostacyclin $\left(\mathrm{PGI}_{2}\right)$ biosynthesis in arteries. Artery 1980;7:488-95.

28 Gray E, Barrowcliffe TW. Inhibition of antithrombin III by lipid peroxides. Thromb Res 1985;37:241-50.

29 Barrowcliffe TW, Gutteridge JM, Gray E. Oxygen radicals, lipid peroxidation and the coagulation system. Agents Actions 1987;22:347-8.

30 Klimov AN, Kozhemakin LA, Pleskov VM, Andreeva LI Antioxidant effect of high-density lipoproteins in peroxidation of low-density lipoproteins. Byulleten Eksperimental noi Biologii i Meditsiny 1987;103:552-5.

31 Ross R. The pathogenesis of atherosclerosis - an update. $N$ Engl f Med 1986;314:488-500

32 Heinle $\mathrm{H}$, Liebich $\mathrm{H}$. The influence of diet-induced hypercholesterolaemia on the degree of oxidation of glutathione in rabbit aorta. Atherosclerosis 1980;37:637-40

33 Szamosi T, Gara I, Venekei I, Javor A, Ceskel R, Knoll J. Serum lipids, lipid peroxides and the care of children with high risk atherosclerotic family historv. Atherosclerosis 1987;68:111-5.

Accepted 17 November 1988

\section{Short term effect of captopril on microalbuminuria induced by exercise in normotensive diabetics}

Cattedra di Patologia Speciale Medica, University of Brescia, II Divisione Medicina, Spedali Civili, 25124

Brescia, Italy Giuseppe Romanelli, MD, researcher

Andrea Giustina, MD, attending physician

Antonino Cimino, MD, physician

Umberto Valentini, MD, registrar

Gianni Giustina, $M D$

professor of medicine

Cattedra di Clinica Medica e Terapia Medica,

University of Brescia, Brescia, Italy

Enrico Agabiti-Rosei, MD, associate professor of medical therapeutics

Giulio Muiesan, MD professor of medicine

Correspondence to: $\mathrm{Dr}$ Romanelli.

Giuseppe Romanelli, Andrea Giustina, Antonino Cimino, Umberto Valentini, Enrico Agabiti-Rosei, Giulio Muiesan, Gianni Giustina

\section{Abstract}

Objective-To investigate whether captopril has any effect on microalbuminuria induced by exercise in normotensive diabetic patients with early stage nephropathy.

rial.

Setting-Outpatient department.

Patients -22 diabetics with stage II nephropathy (urinary albumin excretion rate $<20 \mu \mathrm{g} / \mathrm{min} ; 15$ with type I diabetes and seven with type II), 32 patients with stage III nephropathy (urinary albumin excretion rate $20-200 \mu \mathrm{g} / \mathrm{min} ; 14$ with type I diabetes and 18 with type II), and 10 normal subjects.

Interventions-Four exercise tests on a cycle ergometer: the first two under basal conditions and the third and fourth after subjects had received captopril (two $25 \mathrm{mg}$ doses in 24 hours) or placebo (two tablets in 24 hours).

End Point-Exercised until $\mathbf{9 0 \%}$ of maximum heart rate achieved.

Measurements and main results-Mean urinary excretion one hour after the first two exercise tests was $21 \mu \mathrm{g} / \mathrm{min}$ in normal subjects, $101 \mu \mathrm{g} / \mathrm{min}$ in diabetic patients with stage II nephropathy, and $333 \mu \mathrm{g} / \mathrm{min}$ in those with stage III nephropathy. Similar results were obtained after placebo. After captopril the urinary excretion rate one hour after exercise was significantly decreased in diabetics with stage II $(36 \mu \mathrm{g} / \mathrm{min})$ and stage III $(107 \mu \mathrm{g} / \mathrm{min})$ disease compared with placebo but not in normal subjects. Systolic and diastolic pressures were similar in the three groups after placebo and captopril had been given.
Conclusions-Captopril significantly reduces microalbuminuria induced by exercise in normotensive diabetics without affecting systemic blood pressure. Captopril may reduce renal intracapillary pressure.

\section{Introduction}

Diabetic nephropathy is one of the main causes of increased morbidity and mortality in diabetic patients. ${ }^{2}$ Even before the onset of the clinical syndrome of diabetic nephropathy, which is characterised by persistent proteinuria, progressive decline in glomerular filtration rate, and increased arterial blood pressure (stage IV of diabetic nephropathy), there is a "silent" period of variable duration during which diabetic patients have only microalbuminuria - that is, their mean urinary albumin excretion rate is significantly higher $(20-200 \mu \mathrm{g} / \mathrm{min})$ than that in normal subjects but is detectable only by radioimmunological methods.

Physical exercise can induce an abnormal increase in the urinary albumin excretion rate in diabetics with microalbuminuria while resting (stage III) ${ }^{4}$; it can also induce microalbuminuria in diabetics who do not excrete protein while resting (stage II) and therefore can disclose an early stage of renal disease. Recent studies have shown that chronic inhibition of angiotensin converting enzyme may reduce baseline microalbuminuria in normotensive diabetic patients; such inhibition could be effective in slowing the progression of diabetic nephropathy. The aim of our study was to investigate the short term effect of the angiotensin converting enzyme inhibitor captopril on micro- 